\title{
VALIDAÇÃO DE BUNDLE PARA PREVENÇÃO DE FLEBITE ASSOCIADA A INSERÇÃO DE CATETERES INTRAVENOSOS PERIFÉRICOS EM CRIANÇAS
}

\author{
Erika Anny Costa Cerqueira ${ }^{1}$; Luciano Marques dos Santos ${ }^{2}$; Emily da Cruz Lima ${ }^{3}$; \\ Milena Moreira Brandão ${ }^{4}$
}

1. Voluntária do Programa de Estágio Voluntário de Iniciação Científica. Estudo vinculado ao Projeto "Segurança do paciente pediátrico e sua família: estudo de tecnologias e eventos adversos associados à terapia intravenosa periférica”, Departamento de Saúde, Universidade Estadual de Feira de Santana, e-mail: anny_c@live.com

2. Orientador e coordenador do projeto "Segurança do paciente pediátrico e sua família: estudo de tecnologias e eventos adversos associados à terapia intravenosa periférica”, Departamento de Saúde, Universidade Estadual de Feira de Santana, e-mail: lucmarxenfo@yahoo.com.br

3. Voluntária do Programa de Estágio Voluntário de Iniciação Científica. Bolsista FAPESB. E-mail: emilylima18@ hotmail.com 4. Voluntária do Programa de Estágio Voluntário de Iniciação Científica. Bolsista PIBIT/Cnpq E-mail: milenafsa1995@hotmail.com

PALAVRAS-CHAVE: enfermagem pediátrica; criança hospitalizada; cateterismo periférico.

\section{INTRODUÇÃO}

A prevenção da flebite, que consiste numa das complicações mais frequentes da terapia intravenosa, é essencial para o fornecimento de uma assistência de qualidade, uma vez que esse evento adverso pode causar desconforto para a criança, aumento do tempo de hospitalização, das demandas dos profissionais da enfermagem e do encargo financeiro do hospital. Além disso, sua ocorrência pode estar associada à formação de trombos que poderão ocasionar embolia e danos permanentes ao vaso (POTTER; PERRY, 2013). Dessa forma, é plausível o desenvolvimento de estratégias que auxiliem nesse processo, tal como o bundle.

O bundle consiste num "pacote" de cuidados que devem ser instituídos em conjunto durante a realização de determinada intervenção (RESAR et al., 2012), sendo que alguns estudos mostram que a utilização de bundles auxilia na prevenção de complicações relacionadas à terapia intravenosa, tal como a infecção da corrente sanguínea associada ao cateter venoso central (MENEGUETI et al., 2015; BERTOGLIO et al., 2017).

Ao tentar estabelecer o estado da arte, foi encontrado apenas um artigo (CHO et al., 2015) que aborda o desenvolvimento de bundle para prevenção de flebite associada a cateteres intravenosos periféricos em crianças, mas este não se encontra disponível para download. Dessa forma, na tentativa de responder ao seguinte questionamento: "É possível validar bundle para auxiliar na prevenção de flebite em crianças hospitalizadas?", este estudo teve o objetivo de validar um bundle para prevenção de flebite associada à inserção de cateteres intravenosos periféricos em crianças hospitalizadas, quanto ao conteúdo e à aparência.

\section{MATERIAIS E MÉTODOS}

Trata-se de um estudo metodológico voltado para a validação de um bundle para prevenção de flebite associada à inserção de cateteres intravenosos periféricos em crianças hospitalizadas. Participaram do estudo profissionais da enfermagem que atuam num hospital pediátrico de Feira de Santana, enfermeiras especialistas consultoras de empresas fabricantes de cateteres e que desenvolvem educação permanente, e docentes, de universidades públicas brasileiras, que possuem experiência com validação e assistência hospitalar. O processo de validação ocorreu entre os finais de abril e junho de 2017. 
Para a validação do conteúdo e da aparência do bundle, foi utilizada a técnica Delphi, que consiste num método de validação baseado na obtenção do consenso entre as opiniões de avaliadores (CASTRO; REZENDE, 2009). Os dados coletados na etapa de validação foram digitados no programa Statistical Package for Social Science (SPSS) versão 22.0 e analisados através da estatística descritiva. Estipulou-se como parâmetro de concordância o Índice de Validação de Conteúdo (IVC) igual ou superior a 75\%. Esta pesquisa respeitou os aspectos éticos da Resolução n ${ }^{\circ}$ 466/12 do Conselho Nacional de Saúde (Brasil, 2012), sendo submetido à apreciação do Comitê de Ética em Pesquisa (CEP) da Universidade Estadual de Feira de Santana e foi aprovado sob o parecer de $n^{\circ} 841.612$.

\section{RESULTADOS}

O grupo de avaliadoras, composto por 8 profissionais, foi formado, em sua maioria, por profissionais que trabalham com a população pediátrica $(75 \%)$. Todas as participantes foram do sexo feminino, enfermeiras, com tempo de formação variando de 5 a 33 anos, sendo que $75 \%$ possuem como maior titulação acadêmica a especialização e $25 \%$ dedicam-se apenas à assistência. Entre as que trabalham na assistência, há profissionais que atuam na emergência $(12,5 \%)$, na oncologia $(12,5 \%)$ e na unidade semi-intensiva $(12,5 \%)$ pediátricas. O restante das profissionais exerce atividades de extensão (12,5\%), ensino e gerência (12,5\%), pesquisa e assistência (12,5\%), pesquisa e gerência (12,5\%), e ensino, pesquisa e extensão (25\%).

A validação foi realizada em apenas uma rodada. O bundle obteve IVC global de 0,94 e individuais, por item e categoria, iguais ou superiores a 0,75 (TABELA 1), sendo, portanto, considerado validado. Contudo, mesmo após a validação, passou por algumas alterações a partir das sugestões de avaliadoras e da análise dos pesquisadores.

Tabela 1 - Distribuição do Índice de Validação de Conteúdo segundo linguagem, estrutura e apresentação, relevância das intervenções e aplicabilidade. Feira de Santana, BA, 2017.

\begin{tabular}{lr}
\hline \hline Variável & $*$ *IVC \\
\hline LINGUAGEM, ESTRUTURA E APRESENTAÇÃO & \\
A linguagem é clara e de fácil entendimento & 1,0 \\
A concordância e a ortografia estão corretas & 1,0 \\
O tamanho da fonte e o tipo de letra estão adequados à leitura & 1,0 \\
As cores aplicadas ao texto e ao quadro estão adequadas & 1,0 \\
A composição visual está atrativa e bem organizada & 1,0 \\
A ordem dos cuidados está disposta de forma lógica & 1,0 \\
Os cuidados destinados à inserção estão coerentes com esse tópico & 1,0 \\
O título “Bundle para prevenção de flebite associada à inserção de cateter venoso periférico" & \\
está adequado & $\mathbf{1 , 0}$ \\
**IVC individual &
\end{tabular}

\section{RELEVÂNCIA DAS INTERVENÇÕES}

Higienizar as mãos com água e sabão antes e após a manipulação da criança/adolescente. $\quad 1,0$

$\begin{array}{ll}\text { Utilizar cateteres de menor calibre. } & 0,75\end{array}$

Evitar áreas de articulações. $\quad 1,0$

Realizar antissepsia do local da punção com 03 bolas de algodão estéril embebidas em $\quad 0,88$ clorexidina alcoólica a $0,5 \%$ e com movimentos circulares. Esperar o tempo de 30 segundos para a ação deste antisséptico. Na ausência de clorexidina, utilizar álcool a 70\% ou PVPI tópico respeitando o tempo de 1,5 a 2,0 minutos para realizar a cateterização. Não palpar o local após a realização da antissepsia. 
Manter o hub do cateter estabilizado e com cobertura estéril transparente. Na ausência desta

APLICABILIDADE

O material possui aplicabilidade prática

*IVC - Índice de Validação de Conteúdo

**IVC individual - Índice de Validação de Conteúdo por categoria

***IVC global - Índice de Validação de Conteúdo global incluindo todas as categorias

As sugestões foram relacionadas ao item "clareza e entendimento da linguagem", na categoria "linguagem, estrutura e apresentação". Quanto à categoria "relevância das intervenções", houveram sugestões para o item "utilizar cateteres de menor calibre", "antissepsia do local da cateterização", "estabilização do hub e cobertura" e "estabilização das articulações". No quesito "aplicabilidade" também foram feitas proposições. Todas foram avaliadas e apenas aquelas consideradas pertinentes, com base na literatura, foram aceitas.

\section{DISCUSSÃO}

O bundle produzido neste estudo contem 06 cuidados. Apesar de o Institute for Healthcare Improvement (RESAR et al, 2012) definir que deve-se utilizar de três a cinco intervenções, alguns estudos (HELDER et al., 2013; MENEGUETI et al., 2015) usaram mais de cinco intervenções e obtiveram resultados favoráveis à prevenção de complicações associadas ao cateter.

O bundle não foi desenvolvido por profissionais do serviço de saúde no qual visava-se implementa-lo. No entanto, na tentativa de permitir que estes participassem de alguma forma desse processo, realizou-se a validação de conteúdo e aparência do mesmo. Além disso, como o bundle consiste num "pacote" de cuidados, talvez não fosse necessário a realização da validação de aparência. No entanto, esta foi realizada pois, como uma das estratégias para chamar a atenção dos profissionais, pretendia-se que o material fosse impresso e colorido para ser colocado nas enfermarias e no posto de enfermagem.

No que concerne à relevância das intervenções, mesmo após a validação, itens dessa categoria foram submetidos a alterações a partir de sugestões das avaliadoras e da reavaliação dos pesquisadores. Concernente a esta última, foi inserido o cuidado de higienização as mãos com solução alcoólica, pois há respaldo nas recomendações da INS, CDC e ANVISA. Foi retirada, na terceira intervenção, a parte "cateterizar veias mais calibrosas para a infusão de substâncias irritantes/vesicantes" pois não há embasamento científico claro que confirme essa proposição. Na intervenção sobre as coberturas, por sua vez, foi retirada a recomendação sobre a substituição pois esse cuidado se refere à manutenção do cateter. Acrescente a isso, com a finalidade de objetivar as recomendações, houve modificações na redação dos textos.

Ainda com relação aos itens da categoria "relevância das intervenções", a maioria foi utilizada em bundles (BERTOGLIO et al., 2017; YUAN, 2016) para a prevenção de complicações associadas à terapia intravenosa, seja ela instituída por cateteres periféricos e/ou 
centrais. Apenas para os itens relacionados à estabilização do hub e de articulações não foram encontrados estudos que mencionassem essas intervenções em bundles.

\section{CONCLUSÃO}

O bundle validado consiste num "pacote de intervenções" apto a ser utilizado na prática de profissionais de saúde que assistem à população pediátrica. Essa afirmação é reforçada quando se considera que as intervenções foram embasadas em ECRC, revisões sistemáticas e manuais da INS, CDC e ANVISA.

Este bundle certamente será útil para a prevenção da flebite e consequentemente para a redução do tempo de hospitalização, dos encargos financeiros para o hospital, do sofrimento da criança associado à ocorrência de complicações bem como do tempo gasto pelos profissionais na assistência a essa criança.

\section{REFERÊNCIAS}

BERTOGLIO, S. et al. Improving outcomes of short peripheral vascular access in oncology and chemotherapy administration. The Journal Of Vascular Acess. v. 18, n. 2, p. 89-96, mar. 2017. Disponível em: <https://www.ncbi.nlm.nih.gov/pubmed/28127726>. Acesso em: 08 ago. 2017.

CASTRO, A. V.; REZENDE, M. A técnica Delphi e seu uso na pesquisa de enfermagem: revisão bibliográfica. Rev. Min. Enferm; Minas Gerais, v. 13, n. 3, p. 429-434, jul./set., 2009.

$\mathrm{CHO}, \mathrm{Y} . \mathrm{H}$. et al. Reducing the incidence of phlebitis related to intravenous injection in pediatric patients. Hu Li Za Zhi, v. 62 (supl. 3), p. 49-57, 2015.

HELDER, O. et al. Implementation of a children's hospital-wide central venous catheter insertion and maintenance bundle. BMC Health Services Research, v. 13, 2013.

MENEGUETI, M. G. et al. The Impact of Implementation of Bundle to Reduce Catheter-Related Bloodstream Infection Rates. Journal of Clinical Medicine Research, v. 7, n. 11, p. 857-861, 2015.

POTTER, P. A.; PERRY, A. G. Fundamentos de enfermagem. Rio de Janeiro: Elsevier, 2013. $1568 \mathrm{p}$.

RESAR, $\mathrm{R}$ et al. Using Care Bundles to Improve Health Care Quality. Cambridge, Massachusetts: Institute for Healthcare Improvement, 2012. Disponível em: <http://emergencylaparotomy.org.uk/wpcontent/uploads/2015/11/IHIUsingCareBundlesWhitePaper2012-1.pdf>. Acesso em: 12 jan. 2017.

YUAN, C. et al. Prevention of peripherally inserted central catheter-related infections in very low-birthweight infants by using a central line bundle guideline with a standard checklist. International Journal of Nursing Sciences, v. 3, n. 1, p. 50-53, 2016. Disponível em: <http://www.sciencedirect.com/science/article/pii/S2352013215300399>. Acesso em: 08 ago. 2017. 